\title{
CHEMOMETRIC STRATEGY FOR OPTIMIZATION OF AN ACID DECOMPOSITION METHOD TO DETERMINE THE MINERAL COMPOSITION IN ALMOND PULP (Terminalia catappa Linn.)
}

\author{
Ana Maria Pinto dos Santos ${ }^{\mathrm{a}, *,(1)}$, Liz Oliveira dos Santos ${ }^{\mathrm{a}, \mathrm{b}}$, Lorena de Souza Santos ${ }^{\mathrm{a}}$, Emmanuelle Ferreira Requião Silva \\ João Honorato Santos Neto ${ }^{a}$ and Geovani Cardoso Brandão ${ }^{c}$ \\ aDepartamento de Química Analítica, Instituto de Química, Universidade Federal da Bahia, 40170-115 Salvador - BA, Brasil \\ ${ }^{b}$ Centro de Ciência e Tecnologia em Energia e Sustentabilidade, Universidade Federal do Recôncavo da Bahia, 44085-132 Feira \\ de Santana - BA, Brasil \\ 'Departamento de Ciências Exatas e da Terra, Universidade do Estado da Bahia, 41150-000 Salvador - BA, Brasil
}

Recebido em 04/09/2020; aceito em 12/02/2021; publicado na web em 12/03/2021

\begin{abstract}
In this work, multivariate optimization techniques were applied to develop an acid digestion procedure in digester block using "cold finger" as reflux system to determine minerals in almond pulp samples by inductively coupled plasma optical emission spectrometry. Two-level full factorial design and Box-Behnken design were applied to evaluate and optimize the factors involved in the acid digestion process. In both experimental designs, Function D and Function MR multiple responses were used to establish the method condition for all analytes and with greater digestion efficiency. Two apple and spinach leaves certified reference materials were analyzed to confirm the proposed method accuracy. The digestion efficiency was evaluated by residual carbon content which showed 1.32-1.77\% range. The concentration values found for each element in almond pulp collected in Salvador, Bahia, Brazil in mg $100 \mathrm{~g}^{-1}$ were: $3.08(\mathrm{Ca}), 0.209(\mathrm{Cu}), 0.407(\mathrm{Fe}), 356(\mathrm{~K}), 21.5(\mathrm{Mg}), 0.096(\mathrm{Mn}), 34.4(\mathrm{P})$ and $0.289(\mathrm{Zn})$. The developed method was simple and efficient for almond pulp mineral composition evaluation. This unconventional fruit has nutritional relevance with future application for new food recipes and pharmaceutical products formulation.
\end{abstract}

Keywords: almonds; mineral composition; Box-Behnken design; desirability function; MR function.

\section{INTRODUCTION}

Almond (Terminalia catappa Linn.) is an exotic plant species which belongs to Combretaceae family and is well adapted to Brazilian weather conditions. It is known by popular terms such as "amendoeira da praia", "anoz", "castanhola", "castanheira", "coração-de-nego", "sete-copas", among others., ${ }^{1,2}$ Some studies have reported that the stem bark,,$^{3,4}$ seeds, ${ }^{5}$ leaves ${ }^{6}$ and fruits ${ }^{7,8}$ of this plant have chemical composition, phytoconstituents, medicine properties and biologic activity which provide benefits to human health. However, its fruit is little explored in Brazilian cuisine and, therefore, it can be considered an unconventional food plant (UFP). ${ }^{1,2,9}$ The UFPs class is characterized by different parts of edible vegetables that were not previously consumed and may be underutilized in human diet. These UFPs, when included in daily meals, provide a healthier diet. Some examples are "Chuchu-de-vento" (Cyclanthera pedata (L.) Schrad.), "Cubiu" (Solanum sessiliflorum Dunal), "Jurubeba" (Solanum paniculatum), "Maxixe" (Cucumis anguria L.) and "Oiti" (Licania tomentosa (Benth.) Fritsch.). ${ }^{10,11}$

The nutraceutical potential to improve well-being or reduce risk of disease is emphasized in research about almond fruits medicinal and nutritional characterization. Nagappa et al. ${ }^{12}$ studied the fruit methanolic and aqueous extracts which exhibited good antidiabetic activity in alloxan-induced hyperglycemic rats, which allowed body weight improvement, pancreas $\beta$-cell and lipid profile regeneration. Souza et al. ${ }^{13}$ determined the centesimal composition, fatty acids and microbiological activity in almond pulp, providing the knowledge about nutrient value, functional properties and beneficial effects of this fruit for human physiology, such as prevention and treatment of cardiovascular diseases, cancer, diabetes, inflammatory processes, among others. Costa et al. ${ }^{14}$ quantified the total phenolic and

*e-mail: amps@ufba.br total anthocyanin compounds in almond fruit using near infrared spectroscopy (NIRS) by applying the chemometric regression model in order to obtain a non-destructive analytical method regeneration that is fast, cheap and versatile. Santos et al. ${ }^{8}$ developed flour obtained from the almond pulp dehydration process. The authors performed the flour centesimal composition and physical-chemical parameters determination in order to evaluate the conventional flour partial or integral replacement in the formulation of several food products.

There are several examples of research which demonstrate the use of chemometric tools for analytical methods multivariate optimization in which the factors involved in the process are simultaneously varied to establish a better condition for the analytical method, using statistical and mathematical techniques. ${ }^{15-17}$ For initial investigation of factors, two-level full factorial design has been widely used in order to evaluate the factors effect and interaction on the responses. ${ }^{18}$ After analyzing the experimental design results, the statistically significant variables were selected and submitted to a response surface methodology to obtain the optimum experimental condition of the proposed method. ${ }^{19,20}$

Among the response surface methodologies, the Box-Behnken design is one of the most efficient designs to optimize experiments. This design requires three or more factors for the optimization process and offers as an advantage the fact that it does not contain extreme conditions in the design, avoiding unsatisfactory results that might occur, and the decrease in the number of experiments, making the optimization process more economical when compared to the univariate methodology. ${ }^{21,22}$ In the literature, there are papers that used the Box-Behnken design for analytical methods optimization, aiming the determination of mineral composition and bioactive compounds in food samples, such as cassava starch, ${ }^{23}$ rice, ${ }^{24}$ bean seeds,,${ }^{25}$ rose petals ${ }^{26}$ and starch. ${ }^{27}$

Experimental designs with varied responses require the application of an optimized experimental condition for each of these responses. 
However, it is possible to apply an optimal experimental condition that meets all the answers through mathematical formulations called multiple answers. These tools can reduce costs and time in an experimental design without significantly compromising the analytical response that is sought, due to the reduced number of experiments. The chemometric tools used in this work have already been considered in several studies, and all of them have shown efficiency in the use of multiple response integrated with experimental design. The multiple responses commonly cited in the literature involving chemometric tools are response desirability, proposed by Derringer and Suich, ${ }^{28}$ and MR, proposed by Ferreira et al. ${ }^{21}$ Both multiple responses presented no significant differences according to a study involving Inductively Coupled Plasma Optical Emission Spectrometry ICP OES instrumental parameters performed by Novaes et al. ${ }^{22}$ There are no studies reported in the literature about the use of multiple response to evaluate the efficiency of an acid decomposition sample procedure through availability of the analytes coming from this process, which demonstrates the importance of this investigation.

In this work, multivariate optimization techniques were applied in the development of an efficient acid digestion procedure aiming to determine macroelements $(\mathrm{Na}, \mathrm{Ca}, \mathrm{K}$ and $\mathrm{Mg}$ ) and microelements $(\mathrm{Cu}, \mathrm{Fe}, \mathrm{Mn}, \mathrm{P}$ and $\mathrm{Zn}$ ) in almond pulp (in natura) collected in the city of Salvador, Bahia, Brazil. Two-level full factorial design and Box-Behnken design were applied to evaluate and optimize the proposed method, respectively. The multiple desirability and MR functions were used for optimizing the acid decomposition method according to the analytes availability in aqueous medium. The results of almond mineral composition show the relevance of these UFPs as food alternative sources, when compared to other fruit species.

\section{MATERIALS AND METHODS}

\section{Instrumentation}

A Sartorius ALC/210.4 analytical balance (Goettingen, Germany) was used to weigh samples and certified reference materials (CRMs). A Tecnal TE-040/25 digester block (São Paulo, Brazil) was used to perform acid and oxidative digestion process of almond samples, CRMs (apple and spinach leaves) and blank solutions.

The simultaneous multi-element determination of $\mathrm{Ca}, \mathrm{Cu}, \mathrm{Fe}$, $\mathrm{K}, \mathrm{Mg}, \mathrm{Mn}, \mathrm{Na}, \mathrm{P}$ and $\mathrm{Zn}$ was performed using a Varian Vista PRO inductively coupled plasma optical emission spectrometer (ICP OES) (Mulgrave, Australia), with charge coupled device (CCD) detector and axial viewing. The instrumental parameters were $1.0 \mathrm{~kW}$ radio frequency power, $15.0 \mathrm{~L} \mathrm{~min}^{-1}$ plasma gas flow rate, $1.5 \mathrm{~L} \mathrm{~min}{ }^{-1}$ auxiliary gas flow rate and $1.5 \mathrm{~L} \mathrm{~min}^{-1}$ nebulizer gas flow rate. The analytical wavelengths (nm) used were C (I) 193.027, Ca (II) 422.673, $\mathrm{Cu}$ (I) 324.754, Fe (II) 259.940, K (I) 766.491, Mg (I) 285.213, Mn (II) 257.610, P (I) 177.434 and Zn (I) 213.857, in which (I) represents an atomic emission line and (II) an ionic emission line. All those emission lines used for element measurement were selected based on the data reported in literature..$^{17,29}$ In general, these emission lines are selected according to some criteria, such as: adequate sensitivity for analyte determination according to its concentration in the digested solution; absence of spectral interferences; and better analytical signal-to-background ratio. ${ }^{30}$

\section{Reagents and solutions}

Ultrapure water $(18.2 \mathrm{M} \Omega \mathrm{cm})$ obtained from a Milli-Q water purification system (Millipore, MA, USA) was used for the preparation of all solutions. All chemical reagents were Merck analytical grade (Darmstadt, Germany). For sample digestion, $65 \%$ $\left(\mathrm{m} \mathrm{m}^{-1}\right)$ nitric acid, $98 \%\left(\mathrm{~m} \mathrm{~m}^{-1}\right)$ sulfuric acid and 30\% $\left(\mathrm{v} \mathrm{v}^{-1}\right)$ hydrogen peroxide were used. Stock solutions of $\mathrm{Ca}, \mathrm{Cu}, \mathrm{Fe}, \mathrm{K}, \mathrm{Mg}, \mathrm{Mn}, \mathrm{P}$ and $\mathrm{Zn}$ (1000 to $\left.4000 \mathrm{mg} \mathrm{L}^{-1}\right)$ elements were used to prepare the working standard solutions. A $20000 \mathrm{mg} \mathrm{L}^{-1}$ carbon stock solution was prepared from citric acid to determine the residual carbon content.

The samples were collected in the city of Salvador, Bahia, Brazil. In the laboratory, these fruits were washed with deionized water and grated down to seed using a plastic grater. Each analyzed sample was composed of four fruits which were randomly chosen.

\section{Multivariate optimization of acid digestion procedure}

A two-level full factorial design was used to evaluate the statistical significance of the factors involved in the acid digestion procedure: $\mathrm{HNO}_{3}$ volume (1.5-2.5 mL), $\mathrm{H}_{2} \mathrm{SO}_{4}$ volume $(0.5-1.5 \mathrm{~mL})$ and $\mathrm{H}_{2} \mathrm{O}_{2}$ volume $(0.2-0.8 \mathrm{~mL})$. For $\mathrm{H}_{2} \mathrm{SO}_{4}$, the investigated volume range corresponds to $0.75-2.25 \mathrm{~mol} \mathrm{~L}^{-1}$ final concentration range in the digested sample solution. A Box-Behnken design was used to obtain the optimal experimental conditions. All experiments were carried out in a random order, using $1.0 \mathrm{~g}$ sample mass (fresh). A Multiple Response function (MR) ${ }^{31}$ and Desirability function (D) ${ }^{28}$ were used in order to simultaneously evaluate the responses obtained for all elements. The MR was calculated by the sum of normalized element concentrations, according to the equation:

$$
M R=\sum I_{i} / I_{\text {imax }}
$$

where $M R$ is the multiple response, $I_{i}$ is the emission intensity obtained for each element and $I_{\text {imax }}$ is the maximum value of emission intensity obtained for each element during the experiments. The Desirability function was calculated according to the equation:

$$
\mathrm{D}=\left(\mathrm{d}_{1} \cdot \mathrm{d}_{2} \cdot \mathrm{d}_{3} \ldots \mathrm{d}_{\mathrm{n}}\right)^{1 / \mathrm{n}}
$$

where $\mathrm{D}$ is the multiple response and $\mathrm{d}$ is the linear normalization based on the interval emission intensities.

Sample digestion procedure was also performed in triplicate, considering the central point, in order to evaluate the experimental error. All results were analyzed using Statistica 10.0 software (StatSoft Inc., Tulsa, USA).

\section{Acid and oxidative digestion procedure of almond samples and certified reference material}

The samples were collected in the city of Salvador, Bahia, Brazil. In the laboratory, these fruits were washed in running water to remove particles of dust and sand. Subsequently, they were washed with 3\% $\left(\mathrm{v} \mathrm{v}^{-1}\right)$ Extran solution (Merck, Darmstadt, Germany), rinsed with deionized water and dried with paper towels. Each analyzed sample was composed of four fruits which were randomly chosen. Then, the fruits were peeled with plastic knives to avoid metal contamination, in which the exocarp was discarded. Subsequently, the mesocarp was grated to seed on a plastic grater and the almond samples were homogenized by the quartering method. $1.0 \mathrm{~g}$ of each sample "in natura" was directly weighed in digester tubes, in triplicate, and transferred to a digester block equipped with "cold finger" as reflux system. ${ }^{32}$ Then, $1.8 \mathrm{~mL}$ nitric acid was added, followed by heating at $150{ }^{\circ} \mathrm{C}$ for $1 \mathrm{~h}$. After that, $0.5 \mathrm{~mL}$ sulfuric acid was added and the solution was heated at $180{ }^{\circ} \mathrm{C}$ for $2 \mathrm{~h}$. Finally, $0.5 \mathrm{~mL} 30 \%\left(\mathrm{v} \mathrm{v}^{-1}\right)$ hydrogen peroxide were added twice at $30 \mathrm{~min}$ time intervals. Subsequently, the digested samples were quantitatively transferred to a volumetric flask and the volume completed up to $12 \mathrm{~mL}$ with 
ultrapure water. The method accuracy was confirmed by analyzing two different certified reference materials: apple leaves (NIST 1515) and spinach leaves (NIST 1570a), purchased from National Institute of Standards \& Technology (NIST). These materials were digested using the same procedure applied to the almond samples. All samples were analyzed in triplicate and analytical blank solutions were prepared in same way as the samples. For multielement determination by ICP OES, an analytical calibration curve using standard solutions with $0.75 \mathrm{~mol} \mathrm{~L}^{-1} \mathrm{H}_{2} \mathrm{SO}_{4}$ final concentration was used.

\section{RESULTS AND DISCUSSION}

\section{Optimization of acid and oxidative digestion procedure of almond samples}

Due to the fact that almond pulp has oil in its composition, a mixture of nitric and sulfuric acid is required for its complete decomposition, once the investigated digestion procedure in this work was performed in a digester block with "cold finger", which is a semiopen system. Once the sulfuric acid has a higher boiling point than the nitric acid, the mixture can achieve higher temperatures during the digestion process, providing the decomposition of compounds such as vegetable oils. ${ }^{26}$ This way, a two-level full factorial design was applied to evaluate the statistical significance of the factors involved in the digestion process, which were: nitric acid volume $(\mathrm{NV})$, sulfuric acid volume (SV), and hydrogen peroxide volume (PV). Table 1 shows the factorial design matrix with real and coded values for each factor, as well as the results obtained for each experiment as Multiple Response (MR) and Desirability (D).

Table 1. Matrix of two-level full factorial design with coded and real values for each factor and results obtained as multiple responses for each experiment. Real value between parentheses

\begin{tabular}{cccccc}
\hline \multirow{2}{*}{ Experiment } & \multicolumn{3}{c}{ Volume $(\mathrm{mL})$} & \multirow{2}{*}{$\mathrm{MR}$} & $\mathrm{D}$ \\
\cline { 2 - 4 } & $\mathrm{HNO}_{3}$ & $\mathrm{H}_{2} \mathrm{SO}_{4}$ & $\mathrm{H}_{2} \mathrm{O}_{2}$ & & \\
\hline $\mathbf{1}$ & $-1(1.5)$ & $-1(0.5)$ & $-1(0.2)$ & 7.966 & 0.992 \\
$\mathbf{2}$ & $-1(1.5)$ & $-1(0.5)$ & $1(0.8)$ & 7.837 & 0.958 \\
$\mathbf{3}$ & $-1(1.5)$ & $1(1.5)$ & $-1(0.2)$ & 5.182 & 0.248 \\
$\mathbf{4}$ & $-1(1.5)$ & $1(1.5)$ & $1(0.8)$ & 4.919 & 0.182 \\
$\mathbf{5}$ & $1(2.5)$ & $-1(0.5)$ & $-1(0.2)$ & 7.339 & 0.827 \\
$\mathbf{6}$ & $1(2.5)$ & $-1(0.5)$ & $1(0.8)$ & 7.054 & 0.752 \\
$\mathbf{7}$ & $1(2.5)$ & $1(1.5)$ & $-1(0.2)$ & 6.699 & 0.655 \\
$\mathbf{8}$ & $1(2.5)$ & $1(1.5)$ & $1(0.8)$ & 4.201 & 0.000 \\
$\mathbf{9}$ & $0(2.0)$ & $0(1.0)$ & $0(0.5)$ & 5.430 & 0.324 \\
$\mathbf{1 0}$ & $0(2.0)$ & $0(1.0)$ & $0(0.5)$ & 5.617 & 0.369 \\
$\mathbf{1 1}$ & $0(2.0)$ & $0(1.0)$ & $0(0.5)$ & 5.663 & 0.387 \\
\hline
\end{tabular}

Significant: MR = Multiple Response; D = Desirability function.

Linear modeling using Multiple Response (MR) and Desirability (D) showed high correlation between their regression coefficients $\left(R^{2}=0.963\right)$, indicating low difference between the models, as shown in Table 2. In both multiple responses, the lack of fit test was significant and indicated that the linear model does not adequately describe the relationship between the factors and the response, at $95 \%$ confidence level, as shown by the Analysis of Variance (ANOVA) in Table 3.

However, it was possible to identify the experimental levels which contribute to the increase of analytical signal, with SV at $0.5 \mathrm{~mL}(-1), \mathrm{PV}$ at $0.2 \mathrm{~mL}(-1)$ and $\mathrm{NV}$ at $1.5 \mathrm{~mL}(-1)$, according to effects calculation as shown in Table 4 . The NV factor did not present
Table 2. Comparison between regression coefficients and between the models obtained by the two multiple responses

\begin{tabular}{ccc}
\hline \multirow{2}{*}{ Term } & \multicolumn{2}{c}{ Regression coefficients } \\
\cline { 2 - 3 } & MR & $\mathrm{D}$ \\
\hline Independent & 12.141 & 2.102 \\
$\mathbf{N} \mathbf{V}^{*}$ & -1.993 & -0.528 \\
$\mathbf{S V} *$ & -6.995 & -1.864 \\
$\mathbf{P V}$ & -2.312 & -0.607 \\
$\mathbf{N V}$ by $\mathbf{S V} *$ & 2.837 & 0.754 \\
$\mathbf{N V}$ by $\mathbf{P V}$ & 1.473 & 0.386 \\
$\mathbf{S V}$ by $\mathbf{P V}$ & 4.976 & 1.312 \\
$\mathbf{N V}$ by $\mathbf{S V}$ by $\mathbf{P V} *$ & -3.466 & -0.912 \\
\hline
\end{tabular}

*Significant: MR = Multiple Response; D = Desirability; NV = Nitric acid volume; $\mathrm{SV}=$ Sulfuric acid volume; $\mathrm{PV}=$ Hydrogen peroxide volume .

Table 3. $p$ and $F$ values obtained through analysis of variance (ANOVA) from the two-level full factorial design data (95\% confidence level)

\begin{tabular}{lcccc}
\hline \multirow{2}{*}{ Factor } & \multicolumn{3}{c}{ Multiple Response (MR) } & \multicolumn{2}{c}{ Desirability (D) } \\
\cline { 2 - 5 } & $F$ & $p$ & $F$ & $p$ \\
\hline $\mathrm{NV}$ & 3.056 & 0.222 & 2.562 & 0.251 \\
$\mathrm{SV}^{*}$ & 693.149 & 0.001 & 715.968 & 0.001 \\
$\mathrm{PV}^{*}$ & 82.632 & 0.012 & 82.609 & 0.012 \\
$\mathrm{NV}$ by SV* & 39.952 & 0.024 & 42.775 & 0.023 \\
$\mathrm{NV}$ by PV* & 46.902 & 0.021 & 47.669 & 0.020 \\
SV by PV* & 45.170 & 0.021 & 45.172 & 0.021 \\
NV by SV by PV* & 35.454 & 0.027 & 35.898 & 0.027 \\
Lack of Fit* & 98.490 & 0.010 & 97.975 & 0.010 \\
\hline
\end{tabular}

$*$ Significant: $\mathrm{NV}=$ Nitric acid volume $\mathrm{SV}=$ Sulfuric acid volume $\mathrm{PV}=$ Hydrogen peroxide volume

analytical signal significant increase regarding the used model. These results can be graphically confirmed through analysis of Pareto chart obtained from the multiples responses $\mathrm{MR}$ and $\mathrm{D}$, at $95 \%$ confidence level, as shown in Figure 1.

Considering the levels indications presented by the linear model obtained from the two-level full factorial design and once the model is not statistically representative, a Box-Behnken design was applied in order to define optimal values for the best digestion process experimental condition through a valid model. For this study, the SV factor experimental domain was displaced for lower levels, once it presented the highest negative main effect in the digestion procedure, according to the results of the two-level full factorial design. The matrix of Box-Behnken design and multiple responses is shown in Table 5. For results prediction, the quadratic models described in equations 1 and 2 were obtained through the multiple responses MR and D, respectively.

$\mathrm{MR}=-3.148+14.031(\mathrm{NV})^{*}-4.259(\mathrm{NV})^{2 *}-2.082(\mathrm{SV})-$ $5.620(\mathrm{SV})^{2 *}-10.049(\mathrm{PV})^{*}+5.673(\mathrm{PV})^{2 *}+1.402(\mathrm{NV})(\mathrm{SV})+$ $1.578(\mathrm{NV})(\mathrm{PV})+6.888(\mathrm{SV})(\mathrm{PV})^{*}$

Equation 1

$\mathrm{D}=-0.877+2.450(\mathrm{NV}) *-0.765(\mathrm{NV})^{2 *}-0.498(\mathrm{SV})-1.063(\mathrm{SV})^{2 *}$ $-2.054(\mathrm{PV})^{*}+1.206(\mathrm{PV})^{2 *}+0.312(\mathrm{NV})(\mathrm{SV})+0.313(\mathrm{NV})(\mathrm{PV})$ $+1.315(\mathrm{SV})(\mathrm{PV})^{*}$

Equation 2

The models obtained by the two multiple responses presented a high correlation between the regression coefficients $\left(R^{2}=0.995\right)$. The values of $p$ and $F$ obtained from the analysis of variance are presented in Table 6 and do not indicate a lack of fit, at $95 \%$ confidence level, 
Table 4. Significance of effects for the main factors and their interactions at $95 \%$ confidence level from the two-level full factorial design

\begin{tabular}{|c|c|c|c|c|c|c|}
\hline \multirow{2}{*}{ Factor } & \multicolumn{3}{|c|}{ Multiple Response (MR) } & \multicolumn{3}{|c|}{ Desirability (D) } \\
\hline & Effect & $t(2)$ & $\mathrm{p}$ & Effect & $\mathrm{t}(2)$ & $\mathrm{p}$ \\
\hline NV & -0.153 & -1.748 & 0.222 & -0.037 & -1.601 & 0.251 \\
\hline $\mathrm{SV} *$ & -2.299 & -26.328 & 0.001 & -0.611 & -26.758 & 0.001 \\
\hline PV* & -0.794 & -9.090 & 0.012 & -0.207 & -9.089 & 0.012 \\
\hline $\mathrm{NV}$ by $\mathrm{SV} *$ & 0.552 & 6.321 & 0.024 & 0.149 & 6.540 & 0.023 \\
\hline NV by $\mathrm{PV} *$ & -0.598 & -6.848 & 0.021 & -0.158 & -6.904 & 0.020 \\
\hline SV by PV* & -0.587 & -6.721 & 0.021 & -0.153 & -6.721 & 0.021 \\
\hline NV by SV by PV* & -0.520 & -5.954 & 0.027 & -0.137 & -5.992 & 0.027 \\
\hline
\end{tabular}

*Significant: NV = Nitric acid volume; SV = Sulfuric acid volume; PV = Hydrogen peroxide volume.
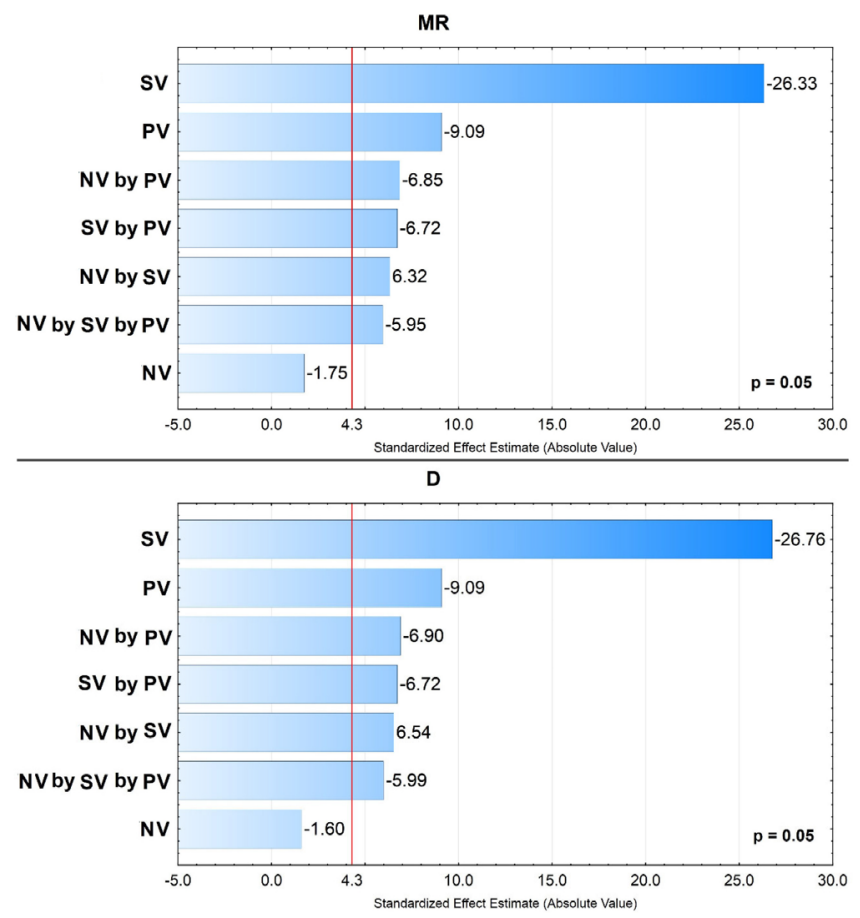

Figure 1. Pareto chart obtained from the two-level full factorial design for Multiple Response function (MR) and Desirability function (D)

demonstrating that both models describe the relationship between the factors and their respective responses well.

The effects study presented in Table 7 showed that all factors for linear and quadratic models were significant, at $95 \%$ confidence level. The SV factor was the most significant one at its lowest level $(0.2 \mathrm{~mL})$, according to the linear model. This is due to the high viscosity of sulfuric acid which reduces the aspiration flow rate and sample solution nebulization by ICP OES. ${ }^{26}$ The second most significant factor was $\mathrm{PV}$ at its highest level $(0.8 \mathrm{~mL})$. This indicates that the $\mathrm{HNO}_{3}$ amount was not enough to make the oxidative process efficient in the digestion. This phenomenon is also complemented by $\mathrm{NV}$ factor which presented its effect with the lowest level $(1.5 \mathrm{~mL})$ to increase the analytical signal due to the need to compensate $\mathrm{H}_{2} \mathrm{O}_{2}$ low concentration in the oxidative system for acidic solution. The only significant interaction was between $\mathrm{SV}$ and $\mathrm{PV}$, corroborating with the previous conclusions that the increase of $\mathrm{H}_{2} \mathrm{O}_{2}$ concentration increases the oxidation capacity, the $\mathrm{H}_{2} \mathrm{SO}_{4}$ decrease allows the sample introduction, and these two factors increase the analytical signal.

The quadratic models also describe a response surface that has a condition which is maximum for the digestion process, considering the NV and SV factors. The response surfaces obtained from the
Table 5. Matrix of Box-Behnken design with coded and real values for each factor and results obtained as multiple responses for each experiment. Real value between parentheses

\begin{tabular}{|c|c|c|c|c|c|}
\hline \multirow{2}{*}{ Experiment } & \multicolumn{3}{|c|}{ Volume (mL) } & \multirow{2}{*}{ MR } & \multirow{2}{*}{$\mathrm{D}$} \\
\hline & $\mathrm{HNO}_{3}$ & $\mathrm{H}_{2} \mathrm{SO}_{4}$ & $\mathrm{H}_{2} \mathrm{O}_{2}$ & & \\
\hline 1 & $-1(1.5)$ & $-1(0.2)$ & $0(0.5)$ & 6.422 & 0.682 \\
\hline 2 & $1(2.5)$ & $-1(0.2)$ & $0(0.5)$ & 4.253 & 0.242 \\
\hline 3 & $-1(1.5)$ & $1(1.0)$ & $0(0.5)$ & 3.914 & 0.190 \\
\hline 4 & $1(2.5)$ & $1(1.0)$ & $0(0.5)$ & 2.866 & 0.000 \\
\hline 5 & $-1(1.5)$ & $0(0.6)$ & $-1(0.2)$ & 5.492 & 0.499 \\
\hline 6 & $1(2.5)$ & $0(0.6)$ & $-1(0.2)$ & 3.881 & 0.191 \\
\hline 7 & $-1(1.5)$ & $0(0.6)$ & $1(0.8)$ & 7.194 & 0.830 \\
\hline 8 & $1(2.5)$ & $0(0.6)$ & $1(0.8)$ & 6.530 & 0.710 \\
\hline 9 & $0(2.0)$ & $-1(0.2)$ & $-1(0.2)$ & 7.193 & 0.817 \\
\hline 10 & $0(2.0)$ & $1(1.0)$ & $-1(0.2)$ & 3.363 & 0.084 \\
\hline 11 & $0(2.0)$ & $-1(0.2)$ & $1(0.8)$ & 6.862 & 0.758 \\
\hline 12 & $0(2.0)$ & $1(1.0)$ & $1(0.8)$ & 6.338 & 0.655 \\
\hline 13 & $0(2.0)$ & $0(0.6)$ & $0(0.5)$ & 6.166 & 0.624 \\
\hline 14 & $0(2.0)$ & $0(0.6)$ & $0(0.5)$ & 6.491 & 0.676 \\
\hline 15 & $0(2.0)$ & $0(0.6)$ & $0(0.5)$ & 6.326 & 0.620 \\
\hline
\end{tabular}

Significant: MR = Multiple response; D = Desirability function.

Table 6. $p$ and $F$ values obtained through analysis of variance (ANOVA) from Box-Behnken design data ( $95 \%$ confidence level)

\begin{tabular}{lcccc}
\hline \multirow{2}{*}{ Factor } & \multicolumn{2}{c}{ Multiple Response (MR) } & \multicolumn{2}{c}{ Desirability (D) } \\
\cline { 2 - 5 } & $F$ & $p$ & $F$ & $p$ \\
\hline$(1) \mathrm{NV}(\mathrm{L})^{*}$ & 143.115 & 0.007 & 143.995 & 0.007 \\
$\mathrm{NV}(\mathrm{Q})^{*}$ & 158.831 & 0.006 & 138.653 & 0.007 \\
$(2) \mathrm{SV}(\mathrm{L})^{*}$ & 322.742 & 0.003 & 317.194 & 0.003 \\
$\mathrm{SV}(\mathrm{Q})^{*}$ & 113.303 & 0.009 & 109.735 & 0.009 \\
$(3) \mathrm{PV}(\mathrm{L}) *$ & 232.077 & 0.004 & 238.297 & 0.004 \\
$\mathrm{PV}(\mathrm{Q}) *$ & 36.532 & 0.026 & 44.670 & 0.022 \\
$\mathrm{NV}(\mathrm{L})$ by SV (L) & 11.939 & 0.075 & 16.047 & 0.057 \\
NV (L) by PV (L) & 8.510 & 0.100 & 9.090 & 0.095 \\
SV (L) by PV (L)* & 103.717 & 0.010 & 102.298 & 0.010 \\
Lack of Fit & 6.348 & 0.139 & 7.081 & 0.126 \\
\hline
\end{tabular}

*Significant: NV = Nitric acid volume; SV = Sulfuric acid volume; $\mathrm{PV}=$ Hydrogen peroxide volume.

Box-Behnken design using the multiples responses MR and D are shown in Figure 2. The effect indication presented by the linear model 
Table 7. Significance of quadratic and linear effects for the main factors and their interactions from the Box-Behnken design, at $95 \%$ confidence level

\begin{tabular}{|c|c|c|c|c|c|c|}
\hline \multirow{2}{*}{ Factor } & \multicolumn{3}{|c|}{ Multiple response (MR) } & \multicolumn{3}{|c|}{ Desirability (D) } \\
\hline & Effect & $\mathrm{t}(2)$ & $p$ & Effect & $\mathrm{t}(2)$ & $p$ \\
\hline$(1) \mathrm{NV}(\mathrm{L})^{*}$ & -1.373 & -11.963 & 0.007 & -0.265 & -12.000 & 0.007 \\
\hline $\mathrm{NV}(\mathrm{Q})^{*}$ & 1.065 & 12.603 & 0.006 & 0.191 & 11.775 & 0.007 \\
\hline$(2) \mathrm{SV}(\mathrm{L})^{*}$ & -2.062 & -17.965 & 0.003 & -0.393 & -17.810 & 0.003 \\
\hline $\mathrm{SV}(\mathrm{Q})^{*}$ & 0.899 & 10.644 & 0.009 & 0.170 & 10.475 & 0.009 \\
\hline (3) $\mathrm{PV}(\mathrm{L})^{*}$ & 1.749 & 15.234 & 0.004 & 0.341 & 15.437 & 0.004 \\
\hline $\mathrm{PV}(\mathrm{Q})^{*}$ & -0.511 & -6.044 & 0.026 & -0.109 & -6.684 & 0.022 \\
\hline NV (L) by SV (L) & 0.561 & 3.455 & 0.075 & 0.125 & 4.006 & 0.057 \\
\hline NV (L) by PV (L) & 0.474 & 2.917 & 0.100 & 0.094 & 3.015 & 0.095 \\
\hline SV $(\mathrm{L})$ by $\mathrm{PV}(\mathrm{L})^{*}$ & 1.653 & 10.184 & 0.010 & 0.316 & 10.114 & 0.010 \\
\hline
\end{tabular}

*Significant: NV = Nitric acid volume; SV = Sulfuric acid volume; PV = Hydrogen peroxide volume.
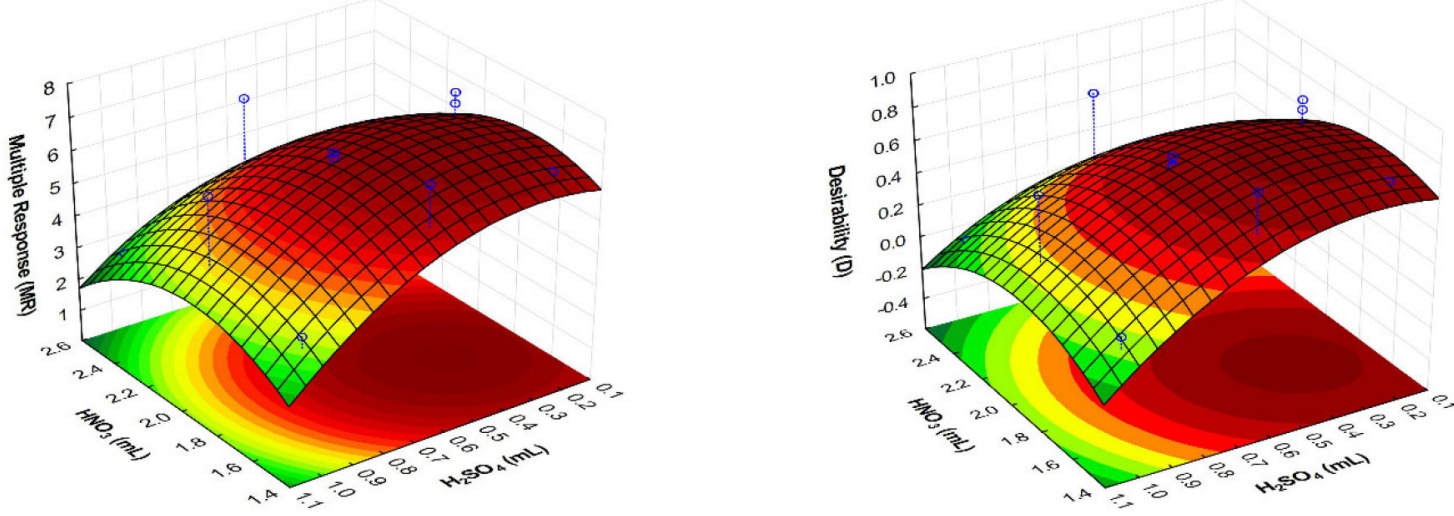

Figure 2. Responses surfaces obtained from the Box-Behnken design for Multiple Response function (MR) and Desirability function (D)

was evidenced through calculation of the critical values obtained from the quadratic models and are described in Table 8.

Table 8. Real critical values for maximum analytical signal $(\mathrm{mL})$

\begin{tabular}{lcccc}
\hline Factor & $\begin{array}{c}\text { Observed } \\
\text { minimum }\end{array}$ & $\begin{array}{c}\text { Critical } \\
\text { value (RM) }\end{array}$ & $\begin{array}{c}\text { Critical } \\
\text { value (D) }\end{array}$ & $\begin{array}{c}\text { Observed } \\
\text { maximum }\end{array}$ \\
\hline $\mathrm{NV}$ & 1.500 & 1.782 & 1.758 & 2.500 \\
$\mathrm{SV}$ & 0.200 & 0.312 & 0.306 & 1.000 \\
$\mathrm{VP}$ & 0.200 & 0.448 & 0.456 & 0.800 \\
\hline
\end{tabular}

Significant: NV = Nitric acid volume; SV = Sulfuric acid volume; PV $=$ Hydrogen peroxide volume.

\section{Analytical method accuracy evaluation by ICP OES}

The proposed method was used to quantify the minerals $(\mathrm{Ca}$, $\mathrm{Cu}, \mathrm{Fe}, \mathrm{K}, \mathrm{Mg}, \mathrm{Mn}, \mathrm{P}$ and $\mathrm{Zn}$ ) by inductively coupled plasma optical emission spectrometry (ICP OES). The residual carbon content (RCC) was $1.32-1.77 \%\left(\mathrm{~m} \mathrm{~m}^{-1}\right)$ for almond pulp, proving the method efficiency for samples acid and oxidative digestion, when compared to other methods described in the literature, once the RCC values obtained for all digested solutions in the present work were similar or lower than those reported in literature for this kind of analysis. ${ }^{26,33,34}$ Limits of detection (LOD) and quantification (LOQ) were calculated according to International Union of Pure and Applied Chemistry (IUPAC) recommendation. ${ }^{35,36}$ Thus, these limits were calculated using the following equations: $\mathrm{LOD}=0.03 \times \mathrm{RSD}_{\text {Blank }} \times \mathrm{CSR} /\left(\mathrm{ISR} / \mathrm{I}_{\text {Blank }}\right)$; $\mathrm{LOQ}=0.10 \times \mathrm{RSD}_{\text {Blank }} \times \mathrm{CSR} /\left(\mathrm{ISR} / \mathrm{I}_{\text {Blank }}\right.$ ), where $\mathrm{RSD}_{\text {Blank }}$ is the analytical blank relative standard deviation $(n=10)$; CSR represents the analyte concentration present in the multi-element reference solution; ISR and $\mathrm{I}_{\mathrm{Blank}}$ are the analytes emission intensities in the reference solution and analytical blank, respectively. ${ }^{36}$ The almond certified reference material was not found for purchasing. Therefore, two vegetal matrix (leaves) certified reference materials (CRM) were analyzed to confirm the accuracy of the proposed method. Table 9 shows the method limits of detection and quantification, as well as the CRM analysis results. In addition, a statistical $t$-test was applied in order to compare the found values with those certified values, for a $95 \%$ confidence level. For all studied elements, the $t$-calculated value was lower than the $4.30 t$-critical value, indicating that there are not significant differences between found values and certified values, which confirm the proposed method accuracy.

Table 10 compares the almond mineral content with other fruits consumed worldwide: atemoya, papaya, melon, avocado and watermelon, considering the data reported by Brazilian Food Composition Table (TACO), ${ }^{38}$ the United States Department of Agriculture (USDA) ${ }^{39}$ and other authors reported in the literature. From this comparison, it can be observed that almond fruit has similar mineral content regarding other fruits, with relatively high concentration of potassium, magnesium and iron when compared to melon, papaya and watermelon and low sodium content when compared to atemoya, avocado and melon. When comparing with the same species the levels of $\mathrm{Ca}, \mathrm{Na}, \mathrm{P}$ and $\mathrm{Zn}$ minerals were similar; however, $\mathrm{Fe}, \mathrm{K}$ and $\mathrm{Mg}$ levels in this work were high. When compared to another almond species, Prunus dulcis, it was noticed that the mineral concentration was lower. Therefore, the results obtained from the almond mesocarp show a nutritional value that enables the development of new products, such as: flour, candy, juice, among others, which can be added as a potential food source of this UFP in the human diet. 
Table 9. Results obtained from analytical parameters analysis by proposed method for elements determination in almond samples ( $n=3$, 95\% confidence level)

\begin{tabular}{cccccc}
\hline Element & LOD $\left(\mathrm{mg} \mathrm{kg}^{-1}\right)$ & LOQ $\left(\mathrm{mg} \mathrm{kg}^{-1}\right)$ & Found value $\left(\mathrm{mg} \mathrm{kg}^{-1}\right)$ & Certified value $\left(\mathrm{mg} \mathrm{kg}^{-1}\right)$ & $t$-calculated value \\
\hline $\mathrm{Ca}$ & 6.0 & 19.9 & $14681 \pm 836$ & $15250 \pm 100^{\mathrm{a}}$ & 2.93 \\
$\mathrm{Cu}$ & 0.15 & 0.49 & $10.42 \pm 1.77$ & $12.22 \pm 0.86^{\mathrm{b}}$ & 4.25 \\
$\mathrm{Fe}$ & 1.0 & 3.4 & $85.7 \pm 3.7$ & $82.7 \pm 2.6^{\mathrm{a}}$ & 3.49 \\
$\mathrm{~K}$ & 2.8 & 9.2 & $15447 \pm 1054$ & $16080 \pm 210^{\mathrm{a}}$ & 2.58 \\
$\mathrm{Mg}$ & 0.77 & 2.58 & $2480 \pm 222$ & $2710 \pm 120^{\mathrm{a}}$ & 4.07 \\
$\mathrm{Mn}$ & 0.10 & 0.33 & $55.3 \pm 2.8$ & $54.1 \pm 1.1^{\mathrm{a}}$ & 1.84 \\
$\mathrm{P}$ & 1.4 & 4.6 & $1529 \pm 168$ & $1593 \pm 68^{\mathrm{a}}$ & 1.64 \\
$\mathrm{Zn}$ & 0.43 & 1.44 & $11.80 \pm 1.20$ & $12.45 \pm 0.43^{\mathrm{a}}$ & 2.33 \\
\hline
\end{tabular}

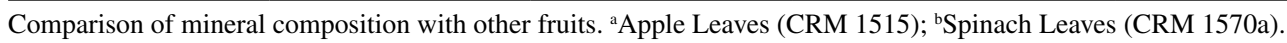

Table 10. Comparison among different fruits mineral composition

\begin{tabular}{|c|c|c|c|c|c|c|c|c|}
\hline \multirow{2}{*}{ Element } & \multicolumn{8}{|c|}{ Mineral composition $\left(\mathrm{mg} 100 \mathrm{~g}^{-1}\right)$} \\
\hline & Almond $^{\mathrm{a}}$ & Atemoya $^{\mathrm{b}}$ & Avocado $^{c}$ & Melon $^{\mathrm{d}}$ & Papaya $^{\mathrm{d}}$ & Watermelon $\mathrm{d}$ & Almond $^{\mathrm{e}}$ & Almond $^{t}$ \\
\hline $\mathrm{Ca}$ & 3.08 & 11.8 & 0.13 & 6 & 11.1 & 7 & 1.19 & 430 \\
\hline $\mathrm{Cu}$ & 0.209 & 0.150 & - & 0.024 & 0.025 & 0.042 & - & 1.1 \\
\hline $\mathrm{Fe}$ & 0.407 & 0.750 & 0.61 & 0.17 & 0.25 & 0.240 & 0.001 & 3.5 \\
\hline $\mathrm{K}$ & 356 & 1362 & 504 & 228 & 146 & 112 & 2 & 685 \\
\hline $\mathrm{Mg}$ & 21.5 & 64.4 & 29 & 10 & 11.1 & 10 & 1.3 & 420 \\
\hline $\mathrm{Mn}$ & 0.096 & 0.350 & - & 0.027 & - & 0.038 & - & 1.5 \\
\hline $\mathrm{Na}$ & 2.12 & 13.3 & 8 & 18 & 1.98 & 1 & 1.95 & 10.5 \\
\hline $\mathrm{P}$ & 34.4 & 47.5 & 54 & 11 & 5.36 & 110 & 22.6 & 705 \\
\hline $\mathrm{Zn}$ & 0.289 & 0.930 & 0.68 & 0.09 & 0.03 & 0.100 & 0.163 & 3.55 \\
\hline
\end{tabular}

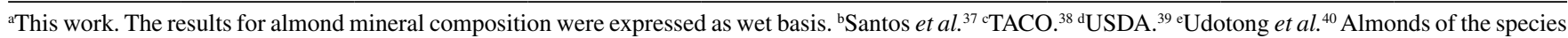
Terminalia catappa $\mathrm{L} .{ }^{\mathrm{f}}$ Yada et al. ${ }^{41}$ Almonds of the species Prunus dulcis.

\section{CONCLUSIONS}

Chemometric tools application to optimize an acid decomposition method evidenced the importance of multivariate study for such procedures. Applying multiple responses with the purpose of obtaining an optimum condition for the best availability of all analytes simultaneously provided a reducing number of experiments and lower reagent consumption. Although two-level full factorial design showed a lack of fit, this contributed to indicate which variables should be further studied using a response surface methodology. The Box-Behnken design, finally, facilitated the interpretation of variables study through a response surface with evident optimal region.

From the mineral components concentration found through this method, it can be considered that almond is an unconventional fruit which can be used for food supplementation, once the mineral content found in it is comparable to other more widely consumed fruits.

\section{ACKNOWLEDGEMENTS}

The authors are grateful to PRONEX/ Fundação de Amparo à Pesquisa do Estado da Bahia (FAPESB), Conselho Nacional de Desenvolvimento Científico e Tecnológico (CNPq) and Coordenação de Aperfeiçoamento de Pessoal de Nível Superior (CAPES) for providing grants, fellowships and financial support.

\section{REFERENCES}

1. Silva, L. P.; de Angelis, C. D.; Bonamin, F.; Kushima, H.; Mininel, F. J.; dos Santos, L. C.; Delella, F. K.; Felisbino, S. L.; Vilegas, W.; da Rocha, L. R. M.; Ramos, M. A. S.; Bauab, T. M.; Toma, W.; Hiruma-Lima, C. A.; J. Ethnopharmacol. 2015, 159, 285.
2. Anand, A. V.; Divya, N.; Kotti, P. P.; Pharmacogn. Rev. 2015, 9, 93.

3. Oliveira, J. T. A.; Vasconcelos, I. M.; Bezerra, L. C. N. M.; Silveira, S. B.; Monteiro, A. C. O.; Moreira, R. A.; Food Chem. 2000, 70, 185.

4. Abiodun, O. O.; Rodríguez-Nogales, A.; Algieri, F.; Gomez-Caravaca, A. M.; Segura-Carretero, A.; Utrilla, M. P.; Rodriguez-Cabezas, M. E.; Galvez, J.; J. Ethnopharmacol. 2016, 192, 309.

5. Ng, S.; Lasekan, O.; Muhammad, K. S.; Hussain, N.; Sulaiman, R.; J. Food Sci. Technol. 2015, 52, 6623.

6. Terças, A. G.; Monteiro, A. S.; Moffa, E. B.; dos Santos, J. R. A.; de Sousa, E. M.; Pinto, A. R. B.; Costa, P. C. S.; Borges, A. C. R.; Torres, L. M. B.; Barros Filho, A. K. D.; Fernandes, E. S.; Monteiro, C. A.; Front. Microbiol. 2017, 8, 1.

7. Marques, M. R.; Paz, D. D.; Batista, L. P. R.; Barbosa, C. O.; Araújo, M. A. M.; Moreira-Araújo, R. S. R.; Cienc. e Tecnol. Aliment. 2012, 32, 209.

8. dos Santos, O. V.; Lorenzo, N. D.; Lannes, S. C. S.; Food Sci. Technol. 2016, 36, 151.

9. Leal, M. L.; Alves, R. P.; Hanazaki, N.; J. Ethnobiol. Ethnomed. 2018, $14,1$.

10. MAPA; Hortaliças não-convencionais: (tradicionais); MAPA/ACS.; Brasília, 2010.

11. Silva, E. F. R.; Santos, B. R. S.; Brandão, G. C.; Silva, M. V. L.; da Silva, E. G. P.; dos Santos, W. P. C.; dos Santos, W. N. L.; dos Santos, A. M. P.; Brazilian Journal of Development 2020, 6, 21576.

12. Nagappa, A. N.; Thakurdesai, P. A.; Rao, N. V.; Singh, J.; J. Ethnopharmacol. 2003, 88, 45.

13. de Souza, A. L. G.; Ferreira, M. C. R.; de Miranda, L. R.; Silvino, R. C. A. S.; Lorenzo, N. D.; Correa, N. C. F.; dos Santos, O. V.; Rev. PanAmazônica Saúde 2016, 7, 23.

14. Costa, R. C.; Uchida, V. H.; Miguel, T. B. V.; Duarte, M. M. L.; Lima, K. M. G.; Anal. Methods 2017, 9, 352. 
15. Bezerra, M. A.; Santelli, R. E.; Oliveira, E. P.; Villar, L. S.; Escaleira, L. A.; Talanta 2008, 76, 965.

16. Correia, F. O.; Silva, D. S.; Costa, S. S. L.; Silva, I. K. V.; da Silva, D. R.; Alves, J. P. H.; Garcia, C. A. B.; Maranhão, T. A.; Passos, E. A.; Araujo, R. G. O.; Microchem. J. 2017, 135, 190.

17. Santos, B. R. S.; Silva, E. F. R.; Minho, L. A. C.; Brandão, G. C.; dos Santos, A. M. P.; dos Santos, W. P. C.; Silva, M. V. L.; dos Santos, W. N. L.; Microchem. J. 2020, 152, 104271.

18. de Santana, F. A.; Portugal, L. A.; Serra, A. M.; Ferrer, L.; Cerdà, V.; Ferreira, S. L. C.; Talanta 2016, 156-157, 29.

19. Lasekan, O.; Abbas, K.; Food Chem. 2011, 125, 713.

20. Santos, B. R. S.; Minho, L. A. C.; Silva, E. F. R.; Sauthier, M. C. S.; Caldas, J. C.; da Silva, E. G. P.; Santana, D. A.; dos Santos, W. N. L.; Food Anal. Methods 2020, 13, 1176.

21. Ferreira, S. L. C.; Bruns, R. E.; Ferreira, H. S.; Matos, G. D.; David, J. M.; Brandão, G. C.; da Silva, E. G. P.; Portugal, L. A.; dos Reis, P. S.; Souza, A. S.; dos Santos, W. N. L.; Anal. Chim. Acta 2007, 597, 179.

22. Novaes, C. G.; Ferreira, S. L. C.; Santos Neto, J. H.; de Santana, F. A.; Portugal, L. A.; Goicoechea, H. C.; Curr. Anal. Chem. 2016, $12,94$.

23. Amorim, F. A. C.; Costa, V. C.; da Silva, E. G. P.; Lima, D. C.; de Jesus, R. M.; Bezerra, M. A.; Food Chem. 2017, 227, 41.

24. da Silva, D. G.; Scarminio, I. S.; Anunciação, D. S.; Souza, A. S.; da Silva, E. G. P.; Ferreira, S. L. C.; Anal. Methods 2013, 5, 998.

25. Santos, W. P. C.; Castro, J. T.; Bezerra, M. A.; Fernandes, A. P.; Ferreira, S. L. C.; Korn, M. G. A.; Microchem. J. 2009, 91, 153.

26. dos Santos, A. M. P.; Silva, E. F. R.; dos Santos, W. N. L.; da Silva, E. G. P.; dos Santos, L. O.; Santos, B. R. S.; Sauthier, M. C. S.; dos Santos, W. P. C.; Microchem. J. 2018, 138, 98.

27. Amorim, F. A. C.; Costa, V. C.; Guedes, W. N.; de Sá, I. P.; dos Santos, M. C.; da Silva, E. G. P.; Lima, D. C.; Food Anal. Methods 2016, 9, 1719.
28. Derringer, G.; Suich, R.; J. Qual. Technol. 1980, 12, 214.

29. dos Santos, A. M. P.; Lima, J. S.; Anunciação, D. S.; Souza, A. S.; dos Santos, D. C. M. B.; Matos, G. D.; Food Anal. Methods 2013, 6, 745.

30. Santos Júnior, A. F.; Matos, R. A.; Andrade, E. M. J.; dos Santos, W. N. L.; Magalhães, H. I. F.; Costa, F. N.; Korn, M. G. A.; J. Braz. Chem. Soc. 2017, 28, 376.

31. Portugal, L. A.; Ferreira, H. S.; dos Santos, W. N. L.; Ferreira, S. L. C.; Microchem. J. 2007, 87, 77

32. dos Santos, A. M. P.; Lima, J. S.; dos Santos, I. F.; Silva, E. F. R.; de Santana, F. A.; de Araujo, D. G. G. R.; dos Santos, L. O.; Food Chem. 2019, 273, 166.

33. Costa, L. M.; Korn, M. G. A.; Castro, J. T.; Santos, W. P. C.; Carvalho, E. V.; Nogueira, A. R. A.; Quim. Nova, 2006, 29, 149.

34. Barbosa, J. T. P.; Santos, C. M. M.; Peralva, V. N.; Flores, E. M. M.; Korn, M.; Nóbrega, J. A.; Korn, M. G. A.; Food Chem. 2015, 175, 212.

35. Thompson, M.; Ellison, S. L. R.; Wood, R.; Pure Appl. Chem. 2002, 74, 835 .

36. Thomsen, V.; Roberts, G.; Burgess, K.; Spectroscopy 2000, 15, 33.

37. dos Santos, W. N. L.; Sauthier, M. C. S.; Cavalcante, D. D.; Benevides, C. M. J.; Dias, F. S.; Santos, D. C. M. B.; Ann. Braz. Acad. Sci. 2016, $88,1243$.

38. TACO; Brazilian table of food composition, $4^{\text {th }}$ ed. rev.; NEPAUNICAMP: Campinas, 2011.

39. USDA; United States Department of Agriculture, available http://ndb. nal.usda.gov/ndb/search/list, accessed February 2020.

40. Udotong, J. I. R.; Bassey, M. I.; Int. J. Eng. Res. 2015, 3, 2454.

41. Yada, S.; Lapsley, K.; Huang, G.; J. Food Compos. Anal. 2011, 24, 469. 